\title{
Brain-Derived Neurotrophic Factor Regulates Cholesterol Metabolism for Synapse Development
}

\author{
Shingo Suzuki, ${ }^{1,2}$ Kazuyuki Kiyosue, ${ }^{3}$ Shunsuke Hazama, ${ }^{1,4}$ Akihiko Ogura, ${ }^{4}$ Megumi Kashihara, ${ }^{1}$ Tomoko Hara, ${ }^{1,2}$ \\ Hisatsugu Koshimizu, ${ }^{1}$ and Masami Kojima ${ }^{1,2}$ \\ ${ }^{1}$ Research Institute for Cell Engineering, National Institute of Advanced Industrial Science and Technology, Ikeda, Osaka 563-8577, Japan, ${ }^{2}$ Solution- \\ Oriented Research for Science and Technology, Japan Science and Technology Agency, Kawaguchi, Saitama 332-0012, Japan, ${ }^{3}$ Neuroscience Research \\ Institute, National Institute of Advanced Industrial Science and Technology, Higashi, Tsukuba 305-8566, Japan, and ${ }^{4}$ Department of Neuroscience, Osaka \\ University Graduate School of Frontier Biosciences, Toyonaka, Osaka 560-0043, Japan
}

Brain-derived neurotrophic factor (BDNF) exerts multiple biological functions in the CNS. Although BDNF can control transcription and protein synthesis, it still remains open to question whether BDNF regulates lipid biosynthesis. Here we show that BDNF elicits cholesterol biosynthesis in cultured cortical and hippocampal neurons. Importantly, BDNF elicited cholesterol synthesis in neurons, but not in glial cells. Quantitative reverse transcriptase-PCR revealed that BDNF stimulated the transcription of enzymes in the cholesterol biosynthetic pathway. BDNF-induced cholesterol increases were blocked by specific inhibitors of cholesterol synthesis, mevastatin and zaragozic acid, suggesting that BDNF stimulates de novo synthesis of cholesterol rather than the incorporation of extracellular cholesterol. Because cholesterol is a major component of lipid rafts, we investigated whether BDNF would increase the cholesterol content in lipid rafts or nonraft membrane domains. Interestingly, the BDNF-mediated increase in cholesterol occurred in rafts, but not in nonrafts, suggesting that BDNF promotes the development of neuronal lipid rafts. Consistent with this notion, BDNF raised the level of the lipid raft marker protein caveolin-2 in rafts. Remarkably, BDNF increased the levels of presynaptic proteins in lipid rafts, but not in nonrafts. An electrophysiological study revealed that BDNF-dependent cholesterol biosynthesis plays an important role for the development of a readily releasable pool of synaptic vesicles. Together, these results suggest a novel role for BDNF in cholesterol metabolism and synapse development.

Key words: brain-derived neurotrophic factor; TrkB receptor; cholesterol; synapse development; lipid rafts; CNS neurons

\section{Introduction}

Among neurotrophins, brain-derived neurotrophic factor (BDNF) is highly expressed in brain and mediates multiple effects on CNS neurons (Bibel and Barde, 2000). One of its remarkable functions is the regulation of synaptic function and development (Poo, 2001). BDNF facilitates long-term potentiation (Figurov et al., 1996; Patterson et al., 1996) and excitatory synaptic transmission by enhancing transmitter release (Lessmann, 1998). Longterm treatment with BDNF increases the number of docked vesicles at synapses and the amount of synaptic vesicle proteins (Takei et al., 1997; Tartaglia et al., 2001). BDNF also induces complex effects on the dendritic arborization of pyramidal neurons (McAllister et al., 1995).

Responses to BDNF are mediated by a tyrosine receptor kinase

Received July 27, 2006; revised April 15, 2007; accepted May 2, 2007.

This work was supported by Grant-in-Aid 40344171 for Scientific Research on Priority Areas (Elucidation of Neural Network Function in the Brain) from the Ministry of Education, Culture, Sports, Science, and Technology of Japan (to M.K.) and Solution-Oriented Research for Science and Technology, Japan Science and Technology Agency (to S.S., T.H., and M.K.). We thank Drs. Masato Okada (Osaka University, Japan), Haruhiko Bito (The University of Tokyo, Japan), and Schuichi Koizumi (University of Yamanashi, Japan) for helpful discussions.

Correspondence should be addressed to Masami Kojima, Research Institute for Cell Engineering, National Institute of Advanced Industrial Science and Technology, 1-8-31 Midorigaoka, Ikeda, 0saka 563-8577, Japan. E-mail: m-kojima@aist.go.jp.

DOI:10.1523/JNEUROSCI.0690-07.2007

Copyright $\odot 2007$ Society for Neuroscience $\quad$ 0270-6474/07/276417-11\$15.00/0
B, TrkB. Binding of BDNF rapidly activates TrkB activity, which in turn triggers multiple intracellular signaling pathways (Reichardt, 2006). The downstream effectors include well characterized signal molecules, such as mitogen-activated protein kinase, phosphatidylinositol 3-kinase, and phospholipase C- $\gamma$. However, how and where BDNF mediates its diverse biological actions remain poorly understood. One intriguing idea is that the distinct signaling or functions of BDNF are mediated in different subcellular compartments. Cholesterol-rich microdomains, called lipid rafts, have been proposed to provide a signaling platform for neurotrophic factor signaling (Simons and Toomre, 2000; Paratcha and Ibanez, 2002). We have shown that lipid rafts are required for BDNF-induced synaptic modulation (Suzuki et al., 2004) and chemotrophic guidance of nerve growth cones (Guirland et al., 2004). Very recently, it was shown that a tyrosine kinase Fyn determines the localization of TrkB in rafts (Pereira and Chao, 2007).

There is also increasing evidence that cholesterol itself is a crucial component of synaptic structure and function. Freezefracture electron microscopy and biochemical studies have shown that cholesterol is enriched in presynaptic terminals (Pfrieger, 2003; Takamori et al., 2006). Pharmacological depletion of cholesterol reduced BDNF-dependent synaptic transmission (Suzuki et al., 2004). In contrast, glial cell-derived cholesterol 
increased the efficacy of synaptic transmission (Mauch et al., 2001). More recently, suppression of the mevalonate pathway was shown to cause defects in learning and memory (Kotti et al., 2006), indicating the importance of cholesterol for the CNS.

Despite these studies, the regulation of cholesterol biosynthesis and metabolism in neurons remains ill-defined. The ratelimiting enzyme of cholesterol synthesis, 3-hydroxy-3methylglutaryl coenzyme A (HMG-CoA) reductase, is expressed in hippocampal neurons (Krijnse-Locker et al., 1995), and radiolabeled cholesterol precursors are converted rapidly into cholesterol in cultured neurons (Saito et al., 1987; Vance et al., 1994). Although these reports indicate that cholesterol content and distribution are controlled in neurons, the actors regulating cholesterol biosynthesis in neurons remain to be identified.

Previously, we demonstrated that both BDNF and cholesterol increase dramatically during cortical development (Suzuki et al., 2004), suggesting that BDNF may regulate cholesterol biosynthesis in the brain. Here we investigate the effect of BDNF on cholesterol biosynthesis in cultured cortical and hippocampal neurons. The results suggest that BDNF elicits cholesterol biosynthesis for the development of presynaptic functions in the CNS.

\section{Materials and Methods}

BDNF was a generous gift from Sumitomo Pharmaceuticals (Osaka, Japan). BDNF was dissolved at $2 \mathrm{mg} / \mathrm{ml}$ in PBS containing $1 \%$ bovine serum albumin (BSA) and was added to the culture medium at various concentrations for $0-5 \mathrm{~d}$, as indicated. The following antibodies were used in this study. For Western blot analysis anti-synaptophysin (1:1000 dilution; Roche Diagnostics, Indianapolis, IN), anti-soluble $N$ ethylmaleimide-sensitive factor attachment protein-25 (anti-SNAP-25; 1:2000; Synaptic Systems, Göttingen, Germany), anti-caveolin-2 (1: 1000; BD Transduction Laboratories, San Jose, CA), anti-neural tubulin (1:5000; Berkeley Antibody Company, Richmond, CA), anti-syntaxin (1:10000; Sigma, St. Louis, MO), anti-transferrin receptor (1:1000; Zymed, San Francisco, CA), anti-phospho-Trk (Y490; 1:1000; Cell Signaling Technology, Beverly, MA), and anti-TrkB (1:1000; BD Transduction Laboratories) were used. The anti-mouse IgG and anti-rabbit IgG secondary antibodies conjugated to horseradish peroxidase were purchased from Jackson ImmunoResearch (West Grove, PA) (1:1000). For immunocytochemistry anti-TrkB $(1: 10 ; 794$, Santa Cruz Biotechnology, Santa Cruz, CA) and anti-synaptophysin (1:200; Santa Cruz Biotechnology), anti-microtubule-associated protein-2 (anti-MAP-2; 1:400; Millipore, Billerica, MA), anti-O4 (1:200; Millipore), and anti-glial fibrillary acidic protein (GFAP; 1:100; Sigma) were used. The anti-mouse IgG, anti-rabbit IgG, and anti-chick IgY secondary antibodies conjugated to Alexa 568 or Alexa 647 were purchased from Invitrogen (Carlsbad, CA) (1:200), and the antibodies conjugated to FITC were purchased from Jackson ImmunoResearch (1:400).

Primary cultures. For biochemical experiments the primary cultures of cerebral cortex and hippocampus were prepared from embryonic day 20 rats as described previously (Suzuki et al., 2002). This procedure was strictly in accordance with the protocols approved by the Institutional Animal Care and Use Committee of the National Institute of Advanced Industrial Science and Technology, Japan. Briefly, cerebral cortices or hippocampi were cut into small pieces and incubated at $37^{\circ} \mathrm{C}$ for $15 \mathrm{~min}$ in papain solution. Cells were separated by $5-10$ gentle trituration passes, using a $10 \mathrm{ml}$ measuring pipette, and were passed through a $70 \mu \mathrm{m}$ cell strainer (Falcon, Oxnard, CA) to remove large debris. Cells were plated on polyethyleneimine-coated plates at $5 \times 10^{4}$ cells $/ \mathrm{cm}^{2}$ for cortical culture or $3 \times 10^{4}$ cells $/ \mathrm{cm}^{2}$ for hippocampal culture and were cultured in medium consisting of $5 \%$ heat-inactivated fetal bovine serum (FBS), $5 \%$ heat-inactivated horse serum, and 90\% DMEM. Cultures were maintained in an incubator with $10 \% \mathrm{CO}_{2}$. After 3-4 din vitro (3-4 DIV) the culture medium was changed to Neurobasal medium (Invitrogen) containing the B27 supplement and glutamine (Invitrogen) as well as the indicated concentrations of BDNF or other drugs as indicated. This preparation also was used for measuring soma size.
For neuron-rich cultures the plated cells were maintained in the presence of $10 \mu \mathrm{M}$ cytosine 1-b-D-arabinofuranoside (Ara-C) until the assays were performed. The population of contaminating non-neuronal cells was determined by immunocytochemistry (see Fig. 3).

Astrocytes were prepared according to a previous report (Ohira et al., 2005). Briefly, dissociated cortical cells were seeded at the density of $5 \times$ $10^{3}$ cells $/ \mathrm{cm}^{2}$ and grown in flasks containing 10\% FBS and 90\% DMEM for $>2$ weeks. After reaching confluence, the cells were washed twice with PBS, harvested with $0.25 \%$ trypsin and $1 \mathrm{~mm}$ EDTA, and then replated in a new flask after a twofold dilution was performed. These procedures were repeated until MAP-2-positive neurons disappeared. Purified astrocytes were plated into six-well plates at a density of $3 \times 10^{5}$ cells/well. The indicated assays were performed after the cultures reached semi-confluence.

For electrophysiology the CA1-CA3 regions of hippocampi were isolated from postnatal day $0-1$ rats and after dissociation. The cells were plated at a density of $3 \times 10^{4}$ cells $/ \mathrm{cm}^{2}$, as described (Nakayama et al., $2005)$. For the first $3 \mathrm{~d}$ the cells were grown in a mixed medium (1:1) containing B27-supplemented Neurobasal medium and 10\% FBScontaining DMEM. Then, the medium was changed to Neurobasal medium containing $3 \mu \mathrm{M}$ Ara-C to prevent proliferation of glial cells. Cells were treated with the indicated drugs from 3-4 to 6-7 DIV.

Cholesterol measurement and cholesterol depletion. After 3-5 d of treatment with the indicated drugs the cells were rinsed with PBS and lysed with lipid lysis buffer [containing the following (in mM): 50 Tris- $\mathrm{HCl}, \mathrm{pH}$ 7.4, 1 EDTA, $150 \mathrm{NaCl}, 10 \mathrm{NaF}, 10 \mathrm{Na}_{2} \mathrm{P}_{2} \mathrm{O}_{7}$, plus $1 \%$ Triton X-100, 100 $\mu \mathrm{M}$ phenylarsine oxide, and protease inhibitor mixture]. Lysates were sonicated, and cellular cholesterol content was determined by using a total cholesterol measurement kit (Wako, Osaka, Japan), which uses an enzyme-coupled reaction in which cholesterol oxidase generates $\mathrm{H}_{2} \mathrm{O}_{2}$ from cholesterol and peroxidase catalyzes the reaction of $\mathrm{H}_{2} \mathrm{O}_{2}$ with 4 -aminoantipyrine to yield a colored product. To estimate total cholesterol levels, we included cholesterol ester hydrolase. Cholesterol was depleted by the addition of $10 \mu \mathrm{M}$ mevastatin (HMG-CoA reductase inhibitor; Sigma) or $100 \mu \mathrm{M}$ zaragozic acid (squalene synthase inhibitor; Sigma) in the presence or absence of BDNF.

Lipid analysis. Sterol extraction was performed as based on the method of Tacer et al. (2002). Cortical neurons $\left(3 \times 10^{6}\right.$ cells $/ 100 \mathrm{~mm}$ Petri dish) and were treated with or without BDNF for $5 \mathrm{~d}$. Cells were homogenized in PBS, and the homogenate was extracted in a 3.6-fold volume of isopropanol $/ n$-heptane $(1: 3 ; \mathrm{v} / \mathrm{v})$ by being vortexed for $30 \mathrm{~s}$. The solution was added to $0.3 \mathrm{M} \mathrm{NaH}_{2} \mathrm{PO}_{4}, \mathrm{pH} 1.0$, and sterols were extracted with constant shaking ( $300 \mathrm{rpm}$, for $30 \mathrm{~min})$. After centrifugation $(9100 \times g$ for $15 \mathrm{~min}$ ), the organic phase was recovered and dried by using a speed vacuum concentrator. Sterols were dissolved in isopropanol and resolved by thin-layer chromatography (TLC) on silica gel 60 TLC plates in hexane/ethyl acetate $(3: 1 ; \mathrm{v} / \mathrm{v})$. Sterols were detected by using anisaldehyde solution [ $p$-methoxy-benzaldehyde/acetic acid/ $\mathrm{H}_{2} \mathrm{SO}_{4}$ /ethanol; 0.93 / $0.38 / 1.25 / 34(\mathrm{v} / \mathrm{v})]$. For densitometric analysis of the bands (see Fig. $1 E, F)$, a CS analyzer version 2.0 (Atto, Tokyo, Japan) was used.

Preparation of lipid rafts. Raft fractionation was performed as described previously (Suzuki et al., 2004). All steps were performed with ice-cold reagents at $4^{\circ} \mathrm{C}$. Briefly, cultured cortical neurons $\left(3 \times 10^{6}\right.$ cells/100 mm Petri dish) were washed with PBS and homogenized in 500 $\mu \mathrm{l}$ of Triton lysis buffer [containing the following (in mM): 50 Tris- $\mathrm{HCl}$, pH 7.4, 1 EDTA, $150 \mathrm{NaCl}, 10 \mathrm{NaF}, 1 \mathrm{Na}_{3} \mathrm{VO}_{4}, 10 \mathrm{Na}_{2} \mathrm{P}_{2} \mathrm{O}_{7}$, plus $1 \%$ Triton X-100, $100 \mu \mathrm{M}$ phenylarsine oxide, protease inhibitor mixture, and protein phosphatase inhibitor mixture]. The lysates were incubated for $30 \mathrm{~min}$, passed 10 times through a $25-\mathrm{G}$ needle, and then mixed with an equal volume of $100 \%(\mathrm{w} / \mathrm{v})$ sucrose in buffer $\mathrm{A}$ [containing the following (in mu): 50 Tris- $\mathrm{HCl}$, pH 7.4, $5 \mathrm{NaCl}, 1 \mathrm{Na}_{3} \mathrm{VO}_{4}$, plus $100 \mu \mathrm{M}$ phenylarsine oxide, protease inhibitor mixture, and protein phosphatase inhibitor mixture]. Then $1 \mathrm{ml}$ of the sucrose-lysate mixture was transferred to a centrifuge tube (50 Ultra-Clear Tubes, $14 \times 89 \mathrm{~mm}$; Beckman Coulter, Palo Alto, CA) and overlaid sequentially with $8 \mathrm{ml}$ of $35 \%(\mathrm{w} / \mathrm{v})$ sucrose in buffer A, followed by $3.5 \mathrm{ml}$ of $5 \%(\mathrm{w} / \mathrm{v})$ sucrose in buffer A. After centrifugation in a Beckman Coulter SW41 rotor for $13 \mathrm{~h}$ at $200,000 \times g$ at $4^{\circ} \mathrm{C}$, the fractions were collected from the top of the gradient. The volume of the first fraction (fraction 1) was $2.5 \mathrm{ml}$, and the 
volumes of the remaining fractions (fractions 2-6) were $2.0 \mathrm{ml}$. Successful fractionation was confirmed by Western blot analysis, using antibodies against raft and nonraft marker proteins (see Fig. $5 \mathrm{~A}$ ).

Western blot analysis. Total lysates were prepared as reported previously (Suzuki et al., 2002). Samples were sonicated with an equal volume of SDS sample buffer [0.125 м Tris-HCl, pH 6.8, 20\% (w/v) glycerol, $4 \%$ $(\mathrm{w} / \mathrm{v})$ SDS, and $10 \%(\mathrm{v} / \mathrm{v}) 2$-mercaptoethanol] and then heated at $100^{\circ} \mathrm{C}$ for 3 min and separated by SDS-PAGE (Suzuki et al., 2004). Samples were transferred to polyvinylidene fluoride membranes (Immobilon P membrane; Millipore). Membranes were blocked in Tris-buffered saline containing $0.2 \%$ Tween 20 (TBST) and 5\% BSA, incubated with the indicated primary antibody in TBST containing $0.5 \%$ BSA (TBSTB) at room temperature for $90 \mathrm{~min}$, and then washed three times with TBST. Membranes then were incubated with peroxidase-conjugated secondary antibodies in TBSTB at room temperature for $30 \mathrm{~min}$ and washed three times with TBST; a signal was detected by using ImmunoStar reagents (Wako).

Filipin staining and immunocytochemistry. Cortical neurons were fixed with $4 \%$ paraformaldehyde at room temperature for $3 \mathrm{~h}$, rinsed three times with PBS, and blocked with 3\% BSA in PBS (PBSB) for $30 \mathrm{~min}$. For immunocytochemistry the cells were permeabilized with $0.2 \%$ Triton $\mathrm{X}-100$ in PBS for $2 \mathrm{~min}$ and then mixed with primary antibodies in PBSB for $90 \mathrm{~min}$, followed by incubation with fluorescent dye-conjugated secondary antibodies for $30 \mathrm{~min}$. For cholesterol staining we used the fluorescent polyene antibiotic filipin (Sigma), which interacts with free cholesterol at the 3- $\beta$-hydroxyl group (Mauch et al., 2001). After fixation the cells were stained with $50 \mu \mathrm{g} / \mathrm{ml}$ filipin for $30 \mathrm{~min}$. Fluorescence images were obtained via a laser confocal microscope (RTS2000; Bio-Rad, Hercules, CA) or with a cooled CCD camera (MRc5; Carl Zeiss, Thornwood, NY) mounted on an epifluorescence microscope (TE230; Nikon, Tokyo, Japan). Captured images were processed via Adobe Photoshop (see Figs. $1 A, 3,6 A$ ). For quantitative analysis the numbers of synaptophysinpositive puncta were determined by using Scion (Frederick, MD) Image software (Suzuki et al., 2004). First we set the threshold for detecting fluorescent spots above the background intensity of that cell and normalized the intensity of the fluorescent spots to the background intensity. The number was estimated as a total area of fluorescent spots and normalized to that of MAP-2-positive cells.

Real-time reverse transcriptase-PCR. Cortical neurons or glial cells were treated with BDNF for the indicated times after overnight starvation, using Neurobasal medium without B27 supplements. Total RNA was isolated from cultured neurons by using the ISOGEN reagent (Nippon Gene, Toyama, Japan), following the manufacturer's instructions. cDNA synthesis and quantitative detection were performed with a 7300 Real Time PCR System (Applied Biosystems, Foster City, CA), using the QuantiTect SYBR Green PCR Kit (Qiagen, Valencia, CA) according to the manufacturer's instructions. The primers for each gene were designed on the basis of the rat sequences: glyceraldehyde-3-phosphate dehydrogenase (GAPDH) (forward primer 5' -TGCAC CACCA ACTGC TTAG-3' and reverse primer 5'-GGATG CAGGG ATGAT GTTC-3'), HMG-CoA reductase (forward primer $5^{\prime}$-GATCT GTGGT TGGAA TTATG AGTGC-3' and reverse primer $5^{\prime}$-TGTAC TTTGA CCCAA GCTGA CG-3'), mevalonate pyrophosphate decarboxylase (forward primer 5'-GGATG AAGCG CTGAT CCTG-3' and reverse primer 5' GGTCC TCTGT GAAGT CCTTG-3'), squalene synthase (forward primer $5^{\prime}$-CGGAA TTTCA TACCC AAGAT GGAC-3' and reverse primer 5'-CGAAG CTGCG ACTGG TCTG-3'), and sterol regulatory element-binding protein-2 (SREBP-2) (forward primer $5^{\prime}$-GAGAC CATGG AGACC CTCAC- $3^{\prime}$ and reverse primer $5^{\prime}$-GAGAA CTCTC CCACT TGATT GCTG-3'). To confirm the amplification specificity, we subjected PCR products to dissociation curve analysis and gel electrophoresis on a $2 \%$ agarose gel to ensure the melting temperature and size of the DNA fragment. Expression levels for each mRNA were estimated by normalization to GAPDH levels measured in the same samples.

Cell viability assay. Cell viability was estimated by diamidinophenylindole (DAPI) staining, which also enabled us to count the number of apoptotic cells, which have condensed nuclei, and the number of normal, intact cells. Cell types were determined by staining with antibodies to MAP-2, GFAP, or O4 to identify neurons, astrocytes, and oligodendrocytes, respectively.
Electrophysiology. For whole-cell recordings pyramidally shaped neurons were selected visually by using DIC optics and continuous flow (1-2 $\mathrm{ml} / \mathrm{min}$ ) of HEPES-buffered artificial CSF (aCSF-H) containing the following (in mM): $124 \mathrm{NaCl}, 5 \mathrm{KCl}, 30$ glucose, $2 \mathrm{CaCl}_{2}, 1 \mathrm{MgCl}_{2}, 0.05$ picrotoxin (Takeda Chemical Industries, Yokohama, Japan), and 25 HEPES, pH 7.4 (Dojin, Tokyo, Japan), plus $0.5 \mu \mathrm{M}$ tetrodotoxin. Solutions in patch pipettes contained the following (in $\mathrm{mM}$ ): 110 Csmethanesulfonate, $10 \mathrm{CsCl}_{2}, 20$ HEPES, $4 \mathrm{MgCl}_{2}, 2.5$ EGTA-Cs, 0.3 GTP-Na $a_{3}$, and 4 ATP- $\mathrm{Na}_{2}, \mathrm{pH}$ 7.3. Miniature EPSCs (mEPSCs) were recorded with a $-70 \mathrm{mV}$ holding potential for $5 \mathrm{~min}$ with the MultiClamp 700A amplifier (Molecular Devices, Sunnyvale, CA) and controlled by a pClamp9 device (Molecular Devices). mEPSCs (supplemental Fig. 1, available at www.jneurosci.org as supplemental material) were analyzed by Clampfit or Mini Analysis (Synaptosoft, Decatur, GA). For the analysis of neurotransmitter release caused by osmotic shock, sucrose was applied with a glass pipette for whole-cell recordings on primary dendrites near the cell body (see Fig. 7) (Rosenmund and Stevens, 1996) with a picopump (World Precision Instruments, Sarasota, FL). For osmotic shock $100 \mathrm{~mm}$ sucrose-containing aCSF-H was applied for $35 \mathrm{~s}$, and the recording was started $5 \mathrm{~s}$ after this stimulation. Sucrose-evoked EPSCs (see Fig. 7) were analyzed by Clampfit or Mini Analysis (Synaptosoft). All chemicals for electrophysiological experiments were obtained from Wako, unless otherwise specified.

Statistical analysis. Data are presented as the means \pm SEM. Student's $t$ test and one-way ANOVA, together with Bonferroni as a post hoc test, were used for statistical analysis.

\section{Results \\ BDNF increases cholesterol content in cultured cortical neurons}

We first examined whether BDNF controlled the cholesterol content of neurons by measuring the cholesterol contents of cortical neurons cultured in the presence or absence of BDNF. The soma and dendrites of the cortical neurons were stained by the cholesterol marker filipin (Fig. 1A). The cholesterol contents were quantified by using cholesterol oxidase in an enzyme-coupled colorimetric assay (see Materials and Methods) (Suzuki et al., 2004). In the present study the neurons were cultured by using serum-free Neurobasal medium and contained the B27 supplement and glutamine when indicated (from 3-4 to 6-7 DIV). This medium does not contain cholesterol or any precursor used for cholesterol biosynthesis (Brewer et al., 1993) and, as described below, suppresses the prosurvival effect of BDNF on cultured neurons.

We found that a $3 \mathrm{~d}$ treatment with BDNF $(200 \mathrm{ng} / \mathrm{ml})$ increased the level of cholesterol in cultured cortical neurons by $38 \pm 1 \%$ (Fig. $1 B$ ) (control, $116 \pm 2 \mathrm{ng} / \mathrm{ml}$; BDNF, $160 \pm 2$ $\mathrm{ng} / \mathrm{ml} ; p<0.01 ; n=3$ independent cultures). Cultured hippocampal neurons also increased the cholesterol content in response to BDNF (Fig. $1 B$ ) (control, $96 \pm 2 \mathrm{ng} / \mathrm{ml}$; BDNF, $115 \pm$ $3 \mathrm{ng} / \mathrm{ml} ; p<0.01 ; n=3$ independent cultures). As well as increasing tyrosine phosphorylation of the TrkB receptor, the cholesterol content was increased significantly by BDNF in a dosedependent manner (Fig. 1C) $(p<0.03)$. In control cultures activation of the $\operatorname{TrkB}$ receptor was not detected (Fig. 1C, top), and endogenous BDNF in the medium was below the detection limit (data not shown), suggesting that endogenous BDNF is insufficient to raise the cholesterol content of the culture. In a time course study a significant increase of cholesterol was observed at $3 \mathrm{~d}$ after BDNF application (Fig. $1 D$ ). To verify that the effect of BDNF was specific for cholesterol biosynthesis, we extracted sterols from cultured cortical neurons and separated them via TLC (Metherall et al., 1996). The major sterol bands on the TLC plates were cholesterol and lanosterol. BDNF stimulation $(200 \mathrm{ng} / \mathrm{ml} ; 5 \mathrm{~d})$ appeared to raise the intensity of cholesterol band specifically (Fig. 1 E, black arrowhead), and densitometric 
analysis revealed that the increase was $38 \pm 12 \%$ (BDNF-treated/BDNF-untreated; $1.38 \pm 0.12 ; p<0.03 ; n=4$ independent experiments). To exclude that the prosurvival effect of BDNF was the cause of the increase in neuronal cholesterol content, we counted the number of MAP2-positive neurons in cultures incubated in the presence or absence of BDNF (200 $\mathrm{ng} / \mathrm{ml} ; 3 \mathrm{~d})$. Quantitative analysis revealed that there was no significant difference in the number of neurons in these cultures (BDNF-treated/BDNF-untreated; $0.98 \pm$ 0.07; $p<0.03)$.

To examine additionally whether BDNF stimulated cholesterol synthesis per se, we sought to normalize cholesterol content to the protein content of the cultures. In contrast to the number of MAP2-positive neurons, the total protein content was increased significantly by $16 \pm$ $3 \%(p<0.03)$ in BDNF-treated cultures $(200 \mathrm{ng} / \mathrm{ml} ; 3 \mathrm{~d})$. This is consistent with a previous report that BDNF elicits de novo protein synthesis in neurons (Takei et al., 2001). Even after normalization (cholesterol/total protein) BDNF significantly increased the cholesterol content $(11 \pm 4 \%$; $p<0.05)$. Because the rise of cholesterol before normalization showed a pattern similar to that after this assessment, we have shown the cholesterol content in all experiments, because we confirmed that the number of MAP-2-positive neurons was not changed by treatment with the indicated drugs.

Together, these results suggest that BDNF elicits cholesterol biosynthesis in CNS neurons.

\section{Involvement of TrkB activation in BDNF-induced cholesterol biosynthesis}

Binding of BDNF to the TrkB receptor induces tyrosine autophosphorylation and activation of the receptor (Reichardt, 2006). To investigate whether TrkB activation was required for BDNF-mediated increases in cholesterol, we applied a general inhibitor of Trk tyrosine kinase, K252a (200 nM), to BDNFtreated $(200 \mathrm{ng} / \mathrm{ml})$ cortical cultures for $3 \mathrm{~d}$. As reported previously (Tapley et al., 1992), K252a completely inhibited BDNFinduced TrkB phosphorylation (Fig. $2 A$, top). We found that $\mathrm{K} 252 \mathrm{a}$ prevented the BDNF-induced increase in cholesterol content (Fig. 2A, bottom, BDNF plus K252a). This result suggests that TrkB activation is involved in BDNF-induced cholesterol biosynthesis. In addition, K252a treatment, which inhibited endogenous activation of the TrkB receptor (Fig. $2 A$, top), did not change the basal cholesterol content of the culture (Fig. $2 \mathrm{~A}$, bottom), indicating that endogenous BDNF is insufficient to stimulate cholesterol biosynthesis in these cultures.

BDNF-induced cholesterol biosynthesis is prevented by specific inhibitors of cholesterol synthesis pathway

Mevastatin is a specific inhibitor of HMG-CoA reductase, which converts HMG-CoA to mevalonate (Goldstein et al., 2006) (see
B

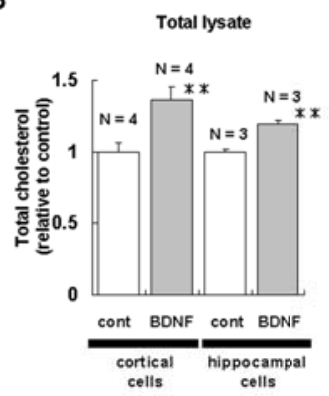

E

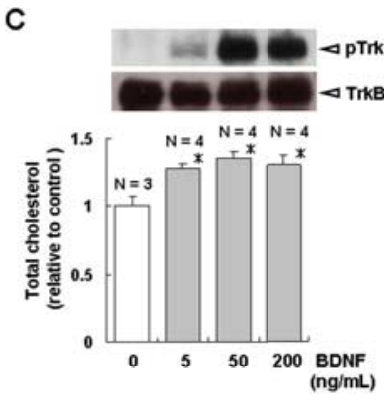

Figure 1. BDNF elicits cholesterol biosynthesis in cultured cortical and hippocampal neurons. Cholesterol content of cortical and

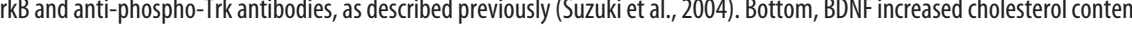
(the means \pm SEM. Asterisks indicate a significant difference from control samples

Fig. 4A, HMGCR). Mevastatin treatment reduces the cholesterol level in cultured cortical neurons (Suzuki et al., 2004). We thus tested whether mevastatin also inhibited BDNF-induced increase of cholesterol content in cultured cortical cells. Treatment of the cells with $10 \mu \mathrm{M}$ mevastatin (statin) for $3 \mathrm{~d}$ completely prevented the BDNF-mediated increase in cholesterol (Fig. $2 B$, BDNF plus statin). Importantly, this inhibition was restored by the addition of mevalonate, the product of the HMG-CoA reductase reaction; cholesterol levels were equivalent to those of cultures treated with BDNF alone (Fig. $2 \mathrm{~B}$, BDNF plus statin plus mevalonate).

We additionally examined the effect of zaragozic acid, a specific inhibitor of squalene synthase (see Fig. 4A, SQS) (Bergstrom et al., 1993), on the BDNF-induced increase in cholesterol. Treatment with zaragozic acid (100 $\mu \mathrm{M} ; 3 \mathrm{~d})$ completely blocked the BDNF effect (Fig. 2C, BDNF plus zaragozic acid). The inhibitory effect of zaragozic acid appeared to be comparable to that of mevastatin (Fig. $2 B, C$ ), supporting the hypothesis that BDNF stimulates the cholesterol synthesis pathway.

\section{BDNF elicits cholesterol biosynthesis in neurons, but not in glial cells}

Cholesterol biosynthesis occurs in both neurons and glial cells (Vance et al., 2005). Because BDNF raised the cholesterol content in cortical cell cultures (Fig. 1) containing a mixture of different cell types, we examined whether or not the BDNF-induced increase in cholesterol content was specific to neurons or glial cells. 
A

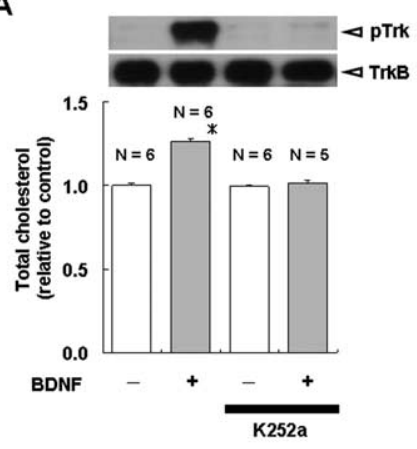

B

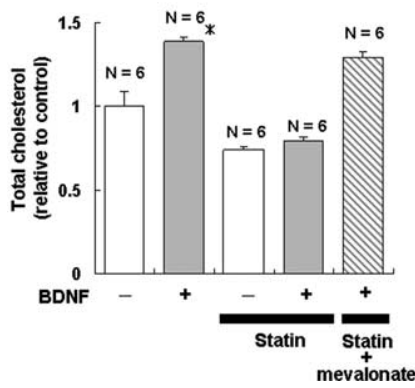

C

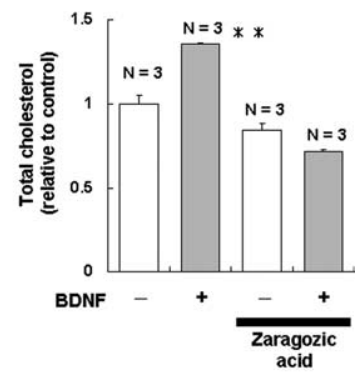

Figure 2. K252a, mevastatin, and zaragozic acid block BDNF-induced cholesterol biosynthesis in cortical neurons. Cholesterol content was measured $3 \mathrm{~d}$ after treatment with the indicated drugs. $A$, Cultured cortical neurons were preincubated with or without $200 \mathrm{~nm} \mathrm{K252a}$ for $1 \mathrm{~h}$ and then incubated with or without $200 \mathrm{ng} / \mathrm{ml} \mathrm{BDNF}$ for $3 \mathrm{~d}$. Top, The inhibitory effect of K252a on BDNF-induced activation of TrkB was investigated as described in Figure 1C. Cell lysates were collected before or $3 \mathrm{~min}$ after treatment with the indicated concentration of BDNF. Bottom, Cholesterol measurements. $\boldsymbol{B}, \boldsymbol{C}$, For the quantification of cholesterol content the cells were treated with the indicated reagents for 0 or $3 \mathrm{~d}$ in the presence or absence of $10 \mu \mathrm{m}$ mevastatin (Statin; $\boldsymbol{B}$ ) and $100 \mu \mathrm{m}$ zaragozic acid (C). Asterisks indicate a statistically significant difference from control group (Student's $t$ test; ${ }^{*} p<0.001 ;{ }^{* *} p<0.003$ ).

Neuron-rich cultures treated with Ara-C, which suppresses the growth of proliferative cells such as astrocytes (Ohira et al., 2005), were incubated in the presence or absence of BDNF $(200 \mathrm{ng} / \mathrm{ml}$; $3 \mathrm{~d}$ ). The Ara-C-treated cultures had a $1.4 \pm 0.21$-fold higher neuronal population than the primary cultures in Figure 1 (Fig. 3A) (MAP-2-positive neurons, $91.2 \pm 0.7 \%$; GFAP-positive astrocytes, $5.4 \pm 0.5 \%$; O4-positive oligodendrocytes, $0.2 \pm 0.2 \%$; others, $5.2 \pm 2.7 \% ; n=3$ independent culture dishes). In these neuron-rich cultures the cholesterol content was increased significantly in response to BDNF (Fig. $3 A)$ ) (1.34 \pm 0.01 -fold compared with control cultures). In primary cultures of astrocytes, however, BDNF treatment $(200 \mathrm{ng} / \mathrm{ml} ; 3 \mathrm{~d})$ did not stimulate cholesterol biosynthesis (Fig. 3C), suggesting that BDNF does not promote cholesterol biosynthesis in glial cells. To test the possibility that neurons might be needed to increase the cholesterol content of glial cells in response to BDNF, we studied the expression of the full-length TrkB receptor (TrkB-FL) in glial cells and neurons in mixed cultures of these two cell types. In agreement with previous reports (Rose et al., 2003; Ohira et al., 2005), immunocytochemistry that used an antibody specific for TrkB-FL (Rasika et al., 1999) demonstrated that TrkB-FL signals were detectable only in MAP-2-positive neurons. No signals were detected in glial cells, even when they were cultured together with MAP-2-positive neurons (data not shown). Together with an earlier result showing that TrkB-FL activation is involved in BDNF-elicited cholesterol biosynthesis under mixed culture conditions (Fig. 2A), this result suggests that TrkB-FL-mediated BDNF signaling promotes cholesterol biosynthesis in neurons rather than in glial cells.

\section{BDNF activates the transcription of cholesterol} biosynthesis enzymes

To identify the mechanism by which BDNF elicits cholesterol biosynthesis, we examined whether BDNF stimulation upregulates the transcription of cholesterol biosynthesis enzymes, because previous work has shown that activation of cholesterol biosynthesis is accompanied by transcriptional control of these enzymes (Shimano, 2001). In this study we used quantitative reverse transcriptase-PCR to quantify the mRNA levels of several cholesterol biosynthesis enzymes. To exclude indirect effects of serum on the activity of genes involved in cholesterol biosynthesis, we cultured neurons in Neurobasal medium minus B27 supplement for $1 \mathrm{~d}$ before adding BDNF. HMG-CoA reductase is the first committed enzyme in the mevalonate pathway (Fig. $4 \mathrm{~A}$ ) (Goldstein et al., 2006). BDNF stimulation of neuron-rich cultures increased the mRNA for HMG-CoA reductase (HMGCR) by $88 \pm 6 \%$ (Fig. $4 B$ ) ( $n=3$ independent culture dishes) within $1 \mathrm{~h}$ of stimulation, and this increase continued for $24 \mathrm{~h}$ (Fig. $4 B$, HMGCR) $(p<0.01)$. BDNF also increased the mRNA for mevalonate pyrophosphate decarboxylase (MPD), which converts mevalonate pyrophosphate into isopentenyl pyrophosphate (Fig. $4 B, \mathrm{MPD})(p<0.03)$, with a time course similar to that of HMGCR. We additionally studied the expression of mRNA for SQS, which catalyzes the first specific step in the cholesterol biosynthetic pathway, and SREBP-2, which is a transcription factor regulating the expression of cholesterol biosynthesis enzymes (Brown and Goldstein, 1999) (Fig. 4B, SQS and SREBP-2). Neither SQS nor SREBP-2 mRNA significantly increased up to $24 \mathrm{~h}$ after BDNF treatment $(p>0.05)$. In contrast, cultured astrocytes did not increase significantly the mRNA levels of any of these enzymes either at 1 or $24 \mathrm{~h}$ after BDNF application (Fig. 4C). These results therefore suggest that BDNF induces the expression of mRNA for cholesterol biosynthesis enzymes in neurons, but not in glial cells, and that the BDNF-stimulated increase in cholesterol content might be controlled at the transcriptional level.

\section{BDNF increases the amount of cholesterol and caveolin-2 in neuronal lipid rafts}

Because lipid rafts are cholesterol-rich microdomains (Simons and Toomre, 2000), we examined whether the cholesterol synthesized in response to BDNF accumulates in raft domains. Lipid raft fractions can be isolated by using the detergent-insoluble property of cholesterol (Simons and Toomre, 2000). We prepared lipid raft fractions from cultured cortical neurons, using our previously reported method (Suzuki et al., 2004). In this preparation cholesterol and the lipid raft marker caveolin-2 were enriched in fraction 2, and a nonraft membrane marker, the transferrin receptor (TfR), was enriched in fraction 6 (Fig. 5A). We compared the cholesterol content in the lipid raft fraction and the nonraft fraction between control and BDNF-treated cultures. BDNF treatment $(200 \mathrm{ng} / \mathrm{ml} ; 3 \mathrm{~d}$ ) led to a robust increase in cholesterol in the lipid raft fraction, but not in the nonraft fraction (Fig. $5 B$, top panels) (fraction $2_{+ \text {BDNF }}, 1.55 \pm 0.02$-fold; fraction $\left.6_{+\mathrm{BDNF}} \mathrm{ND}\right)$. The increase in cholesterol in the lipid raft fraction was similar to the extent of cholesterol increase in total lysates [compare Figs. $5 B$ (top panels, $1.55 \pm 0.02$-fold) and $1 B$ $(1.36 \pm 0.10$-fold)], suggesting that the cholesterol produced in response to BDNF stimulation is a predominant feature of neuronal lipid rafts. In our earlier study the normalization of cholesterol to total protein indicated that BDNF stimulated cholesterol synthesis per se. We therefore sought to normalize cholesterol to the protein content of lipid raft fraction and nonraft fraction. We found that BDNF elicited an increase in protein content in the 
nonraft fraction, but not in the raft fraction (Fig. $5 B$, bottom panels) (nonrafts, $1.49 \pm 0.02$-fold; $p<0.001$ ) and the cholesterol/protein ratio increased in the lipid raft fraction (BDNF-treated/BDNF-untreated; $1.35 \pm 0.02 ; p<0.001)$. Together, these results suggest that lipid rafts may play a structural role in BDNF-dependent cholesterol biosynthesis.

Given that cholesterol is a major component of rafts (Simons and Toomre, 2000), it would be of interest to determine whether BDNF promotes the development of these microdomains, and we therefore examined whether BDNF increased the amount of caveolin-2. Remarkably, BDNF treatment $(200 \mathrm{ng} / \mathrm{ml}$; 3 d) robustly increased the level of caveolin-2 in the raft fraction, whereas caveolin-2 was completely absent from the nonraft fractions of BDNF-treated cultures (Fig. 5B, middle panels). We also examined the effect of BDNF on the level of a nonraft marker protein, TfR. This protein did not show any changes in response to BDNF treatment (Fig. 5B, middle panels). Together, these results suggest that BDNF promotes the development of lipid rafts in CNS neurons by increasing their cholesterol content, which is required for the organization of this raft domain.

\section{BDNF stimulates the increase and accumulation of presynaptic proteins in lipid rafts}

Lipid rafts mediate BDNF signaling in dendritic growth (Suzuki et al., 2004). Herein we have clarified the role of lipid rafts on long-term regulation of synaptic development by BDNF. Treatment with BDNF for 2-3 d exerts the following pleiotropic effects: (1) continuous increase in quantal size as well as impulseevoked synaptic transmission (Wang et al., 1995) and (2) increase in the number of docked vesicles and the number of presynaptic proteins (Takei et al., 1997; Tartaglia et al., 2001). Consistent with these reports, application of BDNF $(200 \mathrm{ng} / \mathrm{ml})$ for $3 \mathrm{~d}$ led to a significant increase in the number of puncta containing the presynaptic protein synaptophysin (Fig. $6 A, C)(2.6 \pm 0.4$-fold increase relative to control cultures; $n=8$ from two independent cultures; $p<0.01$ ).

To understand the role of lipid rafts in BDNF-induced synapse development, we examined the number of presynaptic proteins in the lipid raft and nonraft fractions in BDNF-treated cortical neurons ( $200 \mathrm{ng} / \mathrm{ml} ; 3 \mathrm{~d}$ ). Remarkably, BDNF treatment resulted in a striking increase in the number of presynaptic proteins in lipid rafts (Fig. 6B). However, BDNF did not affect the numbers of these presynaptic proteins in the nonraft fraction. These results suggest that the BDNF-induced increase in presynaptic proteins during synapse development is associated specifically with the lipid raft microdomains.

This finding was supported by the following experiments. First, we examined the effect of a lipid raft disrupter mevastatin on the BDNF-induced increase in the number of synaptophysinpositive presynaptic puncta. Quantitative assessment demonstrated that mevastatin suppressed the BDNF increase in the
B

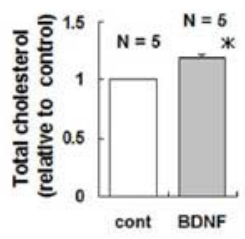

C
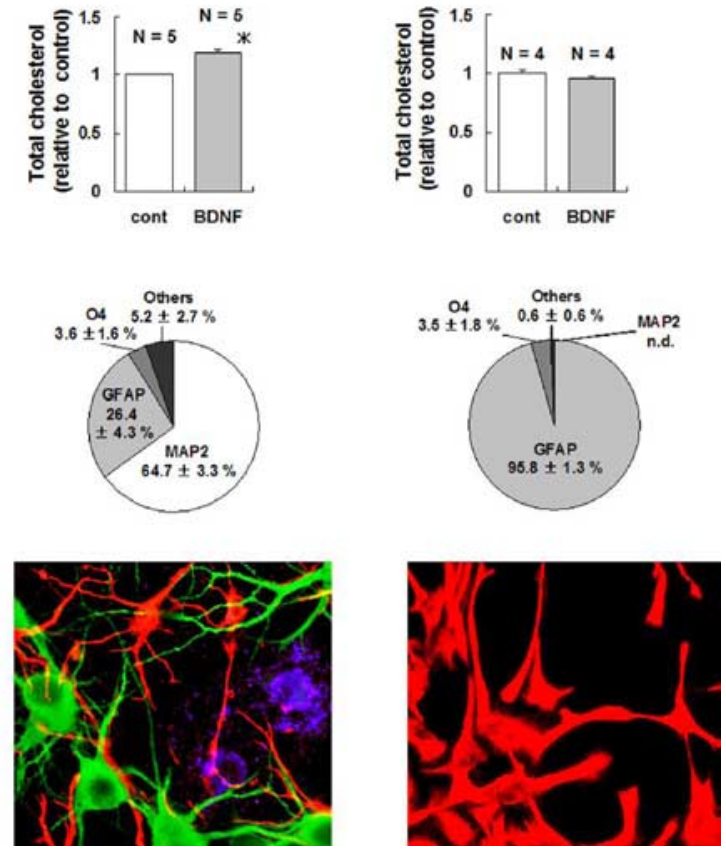
MAP2 GFAP 04

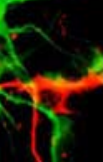

Figure 3. BDNF elicits cholesterol biosynthesis in neurons, but not in glial cells. $\boldsymbol{A}, \boldsymbol{B}$, Cortical cells were cultured in the presence
or absence of BDNF $(200 \mathrm{ng} / \mathrm{ml} ; 3 \mathrm{~d})$ and in the presence $(\boldsymbol{A})$ or absence $(\boldsymbol{B})$ of $1 \mu \mathrm{m}$ Ara-C. $\boldsymbol{C}$, Astrocyte cultures were treated with

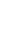
BDNF (200 ng/ml; $3 \mathrm{~d}$ ). Cholesterol content (top) was determined. Cell type and fraction of the population (middle and bottom) significant increase in cholesterol content in response to BDNF. The asterisks indicate a statistically significant difference between control and BDNF samples (Student's $t$ test; ${ }^{*} p<0.001$ ). Scale bar, $10 \mu \mathrm{m}$.

number of synaptophysin-labeled puncta (Fig. 6C) (BDNF plus statin, $1.0 \pm 0.2$-fold). Neurons treated with mevastatin alone showed no significant change in the number of the puncta (Fig. 6C) ( - BDNF plus statin, $0.58 \pm 0.1$-fold; $p>0.08$ ). Quantitative analysis of soma size revealed that neither BDNF nor mevastatin affected the average soma size of MAP-2-positive neurons (data not shown), suggesting that BDNF promotes the development of the synapse, but not the cell body, via the stimulation of cholesterol synthesis.

Second, consistent with previous reports (Takei et al., 1997; Tartaglia et al., 2001), BDNF (200 ng/ml; $3 \mathrm{~d}$ ) increased the amount of presynaptic protein (Fig. $6 \mathrm{~B}, \mathrm{BDNF}$ ). This effect of $\mathrm{BDNF}$, however, was prevented by mevastatin and zaragozic acid (Fig. 6D, BDNF plus statin; E, BDNF plus zaragozic acid). The amount of the neuronal marker protein class III tubulin (TUJ1) was not affected by these inhibitors. Moreover, zaragozic acid and mevastatin similarly inhibited the BDNF-induced increase in cholesterol, additionally supporting the hypothesis that BDNFdependent cholesterol synthesis is crucial for synapse development.

Third, we previously showed that lipid rafts exhibited a gradual increase in the amount of BDNF and TrkB during development and that the amount of lipid raft-specific components, such as cholesterol and caveolin-2, increased during postnatal stages of development (Suzuki et al., 2004). Here we investigated the distribution of presynaptic proteins in lipid rafts during cortical development. Western blotting demonstrated that presynaptic proteins increased during the development of the cerebral cortex (data not shown). These results together suggest that lipid rafts and cholesterol biosynthesis play a crucial role in BDNF-induced synapse development. 
A

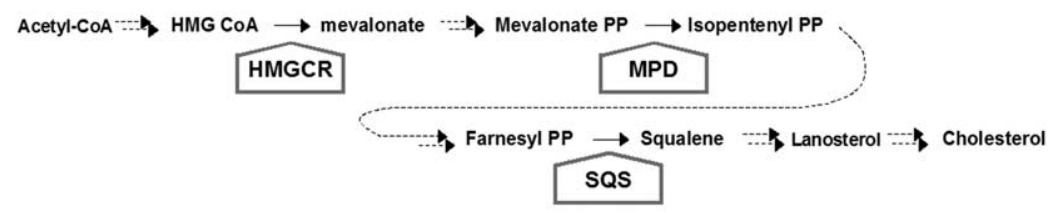

B
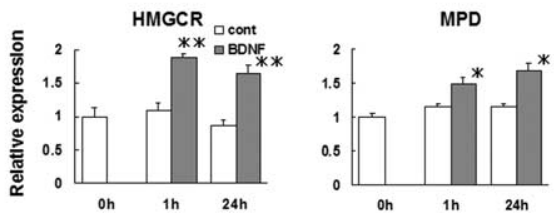

Neuron-rich cultures

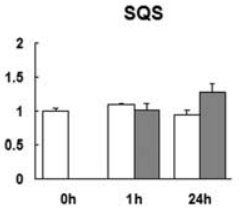

C
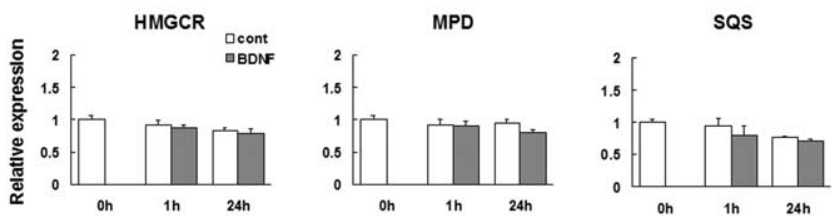

Figure 4. BDNF upregulates the mRNA levels of several cholesterol biosynthesis enzymes in neurons, but not in glial cells. $\boldsymbol{A}$, The mevalonate pathway in mammalian cells. Acetyl-CoA is converted to cholesterol via a pathway containing $>20$ enzymes (Goldstein et al., 2006). The enzymes in which the mRNA was measured are shown in bold. B, C, Cortical cells were cultured for $3 \mathrm{~d}$ in serum-containing medium. Astrocytes were cultured as described in Figure 3. The medium was changed to serum-free Neurobasal medium without the B27 supplement, and the cells were incubated overnight. On the next day, the cells were treated with 200 $\mathrm{ng} / \mathrm{ml} \mathrm{BDNF}$ for 0,1 , or $24 \mathrm{~h}$, and total RNA was isolated. mRNAs of the indicated enzymes were quantified and normalized to that of GAPDH. Results shown are the means \pm SEM from three or four mRNA preparations from independent culture dishes. Asterisks indicate a statistically significant difference from control cultures (Student's $t$ test; ${ }^{*} p<0.03 ;{ }^{* *} p<0.01$ ).

\section{BDNF-elicited cholesterol biosynthesis increases} neurotransmitter release by furnishing a readily releasable pool of synaptic vesicles

To elucidate further the physiological role of BDNF-elicited cholesterol biosynthesis on synaptic function, we performed wholecell recordings on cultured hippocampal neurons (6-7 DIV), which increased cholesterol in response to BDNF (Fig. $1 B$ ). We first recorded spontaneous mEPSCs in the presence or absence of BDNF and/or mevastatin (Nakayama et al., 2005). The cultured hippocampal neurons at this stage, however, exhibited a very small number of mEPSCs (supplemental Fig. $1 A$, available at www.jneurosci.org as supplemental material). We found no significant effect of BDNF (200 ng/ml; $3 \mathrm{~d}$ ) and/or mevastatin on the spontaneous synaptic transmission (supplemental Fig. $1 B$, available at www.jneurosci.org as supplemental material).

However, our previous results (Fig. 6) suggest that BDNF allows for the development of a presynaptic mechanism. It also was reported that endogenous BDNF promotes mobilization and/or docking of synaptic vesicles to presynaptic zones in vivo (PozzoMiller et al., 1999). We therefore speculated that BDNF may promote the development of a readily releasable pool (RRP) of synaptic vesicles, corresponding to docked synaptic vesicles (Rosenmund and Stevens, 1996). The docked vesicles are quantitated by the analysis of the neurotransmitter release evoked by hypertonic solutions containing sucrose, which elicits the fusion of a RRP of vesicles to the plasma membrane independently of intercellular $\mathrm{Ca}^{2+}$ concentration (Rosenmund and Stevens, 1996).

We cultured 3-4 DIV hippocampal neurons in the presence or absence of $200 \mathrm{ng} / \mathrm{ml} \mathrm{BDNF}$ for $3 \mathrm{~d}$, and at 6-7 DIV a hyper-
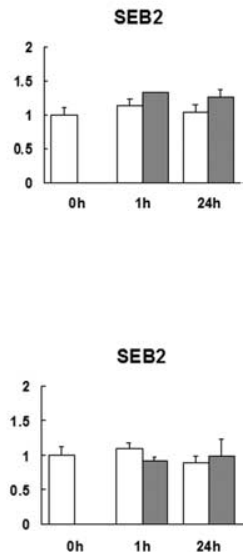

tonic solution containing $100 \mathrm{~mm}$ sucrose was applied according to the method of Rosenmund and Stevens (1996). Remarkably, BDNF-treated neurons exhibited a robust increase in the event number of sucrose-evoked EPSCs under these conditions, whereas untreated cells showed no such response (Fig. 7A), suggesting that BDNF promotes the development of a RRP of vesicles, but not spontaneous neurotransmitter release, in cultured hippocampal neurons at this stage. Quantitative analysis demonstrated that the BDNF effect was significant (Fig. $7 B, C)$ (BDNF at $p<0.05$ compared with control).

We next examined the physiological role of BDNF-elicited cholesterol synthesis in the development of a RRP of vesicles. To this end we applied $10 \mu \mathrm{M}$ mevastatin and $200 \mathrm{ng} / \mathrm{ml} \mathrm{BDNF}$ for $3 \mathrm{~d}$ and analyzed the neurotransmitter release evoked by the hypertonic solution. Mevastatin prevented the BDNF-induced increase in the frequency of sucrose-evoked EPSCs (Fig. $7 B, C)$ (BDNF plus mevastatin at $p<0.05$ compared with BDNF at $p>0.05$, compared with control). Treatment with mevastatin alone had no significant effect (Fig. $7 B, C)$ (mevastatin at $p<0.001$ compared with $\mathrm{BDNF}$ and at $p>0.05$ compared with control). These data suggest that BDNF-elicited cholesterol biosynthesis is a crucial step in the maturation of RRP.

We also analyzed the amplitude of sucrose-evoked EPSCs (Fig. $7 B, D$ ). Pretreatment with BDNF increased the amplitude by $1.96 \pm 0.27$-fold (Fig. $7 D$ ) (BDNF at $p<0.001$ as compared with control). However, mevastatin attenuated the amplitude increase by BDNF (Fig. 7D, BDNF plus mevastatin). Mevastatin alone had no significant effect (Fig. 7D). Hypertonic solution elicits a massive release of neurotransmitter from docked synaptic vesicles and leads to an increase in the amplitude of the EPSCs in a coincidental manner (Rosenmund and Stevens, 1996). These results suggest that BDNF promotes the development of presynaptic function involving a RRP of vesicles, rather than a postsynaptic function, by stimulating cholesterol biosynthesis.

\section{Discussion}

Accumulating evidence has demonstrated the association of defects in cholesterol homeostasis with neurological diseases (Maxfield and Tabas, 2005). In Huntington's disease (HD) the expanded glutamate tract in the huntingtin protein elicits neuronal cell death via the reduction of cholesterol biosynthesis (Valenza et al., 2005). The reduction of BDNF content in HD brains suggests a causal relationship between BDNF signaling and cholesterol metabolism (Zuccato et al., 2001).

Despite such evidence, the regulation of cholesterol metabolism in CNS neurons remains ill defined. The present study investigated the effect of BDNF on cholesterol biosynthesis in cultured CNS neurons. The results suggest that BDNF elicits cholesterol biosynthesis for the development of presynaptic functions. 
A

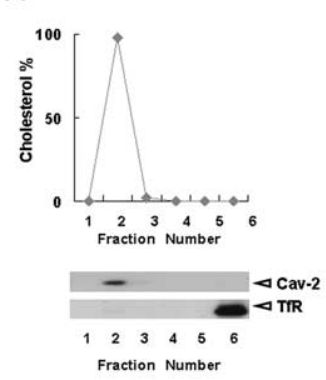

$B$
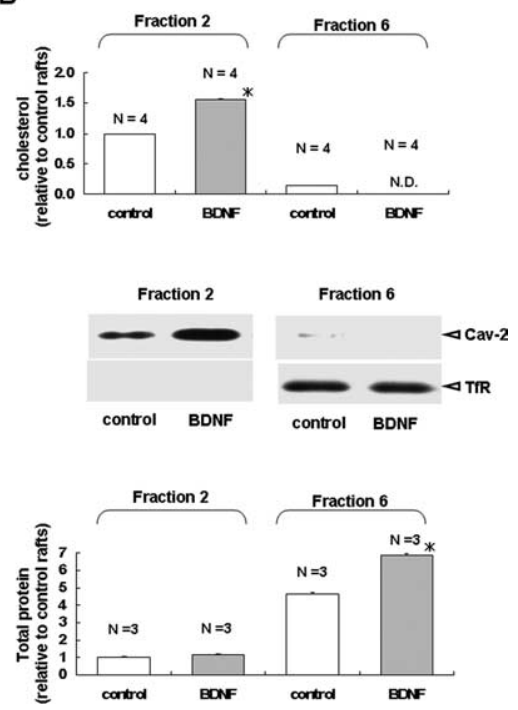

Figure 5. BDNF increases the amount of cholesterol and caveolin-2 in neuronal lipid rafts. Cortical neurons were cultured in the presence or absence of BDNF ( $200 \mathrm{ng} / \mathrm{ml})$ for $3 \mathrm{~d}$. $A$, Lipid raft preparation. Cultured cortical neurons were homogenized in ice-cold lysis buffer containing Triton X-100 and centrifuged in discontinuous 5-35\% sucrose gradients. Six fractions (from top to bottom) were collected. Top, The graph shows the cholesterol content in each fraction as a percentage of the total measured cholesterol, revealing peak cholesterol in the raft fraction (fraction 2). Bottom, Six fractions were separated on SDS-PAGE and immunoblotted for the indicated proteins. The lipid raft marker caveolin-2 is enriched in fraction 2, for which cholesterol concentration is the highest, whereas a nonraft marker protein, TfR, is concentrated in fraction 6. B, Effect of BDNF on the amount of cholesterol, total protein, caveolin-2, and TfR. Fractions 2 and 6 were used to represent lipid rafts and nonraft domains, respectively. Top, BDNF significantly increased cellular cholesterol in the raft fraction, but not in the nonraft fraction. Results are presented relative to the control group in fraction 2. Middle, BDNF increased the amount of caveolin- 2 in rafts but did not affect the distribution of the TfR. Bottom, BDNF significantly increased the total protein content of the nonraft fraction. Results are presented relative to the control group in fraction 2 . The asterisks indicate a statistically significant difference from the control (Student's $t$ test; ${ }^{*} p<0.001$ ).

\section{BDNF regulates cholesterol biosynthesis in neurons}

A key finding of this study is that long-term treatment with BDNF promotes cholesterol biosynthesis in neurons. To our knowledge, this is the first demonstration that growth factor regulates cholesterol biosynthesis in the CNS. This notion is confirmed by a number of biochemical studies: (1) two distinct quantitative methods revealed that BDNF led to a $15-40 \%$ increase in cholesterol content of cultured neurons; (2) BDNF upregulated the level of mRNA for cholesterol biosynthesis enzymes; (3) BDNF enhanced cholesterol biosynthesis in neurons, but not in glial cells; (4) pharmacological studies that used inhibitors of the cholesterol synthesis pathway additionally support the implications of this study; and (5) the notion that BDNF regulates cholesterol synthesis per se rather than mediating the redistribution of cholesterol inside cells was supported by the finding that BDNF-mediated increase in cholesterol biosynthesis still could be seen after normalizing for protein content, although whether the cholesterol synthesized in response to BDNF is redistributed from one region to another is an interesting but nonetheless ill-defined issue (Goldstein et al., 2006).

As shown previously (Reichardt, 2006), BDNF-induced TrkB activation is rapid and transient (supplemental Fig. 2, available at www.jneurosci.org as supplemental material). However, the effect of BDNF on cholesterol synthesis was significant after $3 \mathrm{~d}$ of treatment, suggesting that BDNF-dependent cholesterol synthesis can be categorized as a long-term effect of neurotrophins (Bi- bel and Barde, 2000). How the transient activation of the Trk receptor leads to a long-term effect of neurotrophins has been resolved only partially (Chao, 2003). There is substantial evidence demonstrating that (1) the morphological differentiation of pheochromocytoma (PC12) cells is accompanied by sustained Erk activity (Qui and Green, 1992) and that (2) ankyrin-rich membrane-spanning proteins play a role as scaffold molecules in the Trk receptor-dependent promotion of Erk activity (Arévalo et al., 2004). We reported that lipid rafts might be crucial for BDNF-dependent synaptic modulation, but not for neuronal survival (Suzuki et al., 2004). Future experiments will be designed to understand the signaling mechanism of BDNF-induced cholesterol biosynthesis.

Recently, the role of cholesterol in synapse development and synaptic function has been discussed extensively (Barres and Smith, 2001; Pfrieger, 2003). Mauch et al. (2001) demonstrated that glia-derived cholesterol enhances synaptogenesis, suggesting that the interaction between neurons and glial cells plays a crucial role in cholesterol-mediated synaptogenesis (Pfrieger, 2003). On the other hand, neurons themselves produce cholesterol and related molecules (Saito et al., 1987; Vance et al., 1994). Pharmacological inhibition of cholesterol biosynthesis affects axonal and dendritic morphogenesis (de Chaves et al., 1997; Fan et al., 2002; Pooler et al., 2006), and depletion of cholesterol by methyl- $\beta$ cyclodextrin reduces the number of hippocampal spines (Hering et al., 2003). The absence of the gene for cholesterol 24hydroxylase causes significant defects in learning and memory (Kotti et al., 2006). The present study indicates that BDNF promotes synapse development via the stimulation of cholesterol biosynthesis and hypothesizes a novel role of neurotrophins on lipid metabolism in brain.

K252a, a general inhibitor of TrkB kinase activity, inhibited BDNF-induced cholesterol biosynthesis, suggesting that the $\mathrm{BDNF} / \mathrm{TrkB}$ signaling is involved in cholesterol biosynthesis. In human fibroblasts platelet-derived growth factor (PDGF) treatment induces cholesterol biosynthesis via activation of phosphatidylinositol 3-kinase (Demoulin et al., 2004). However, treatment of cortical neuron cultures with a phosphatidylinositol 3-kinase inhibitor failed to suppress BDNF-induced cholesterol biosynthesis (BDNF and LY294002-treated/LY294002-treated; $1.22 \pm 0.02 ; p<0.0001$ ), suggesting that the signaling pathway used by BDNF to activate cholesterol biosynthesis is different from that used by PDGF.

Twenty enzymes involved in cholesterol biosynthesis have been identified previously (Goldstein et al., 2006), suggesting the presence of a complex regulatory network controlling de novo cholesterol synthesis. We found that BDNF increased the transcription of genes encoding these enzymes in neurons, but not in glial cells. The significant and sustained increase in the level of the gene encoding HMGCR, the most rate-limiting enzyme of cholesterol synthesis (Goldstein et al., 2006), could lead to overall activation of cholesterol synthesis. Additionally, the genes studied here exhibited distinct time courses in their activations after BDNF stimulation (Fig. 4), suggesting that BDNF induces spatial and temporal regulation of the production of the intermediates of cholesterol synthesis (Goldstein et al., 2006).

\section{Cholesterol synthesized in response to BDNF accumulates in lipid rafts: implications for synapse development}

To understand the biological role of BDNF-promoted cholesterol biosynthesis, we tested whether BDNF promotes the accumulation of the newly synthesized cholesterol in rafts. Remarkably, BDNF increased the amount of cholesterol in the raft 
A

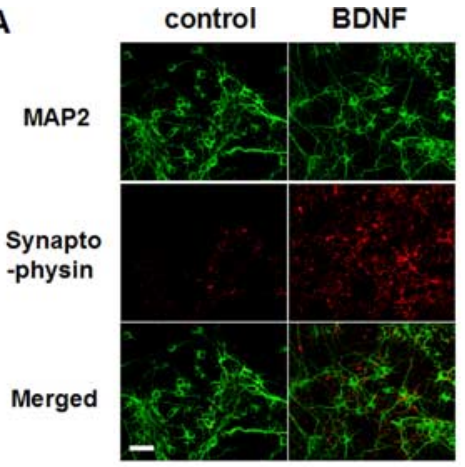

C

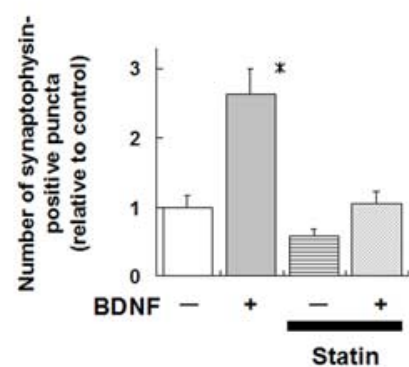

E

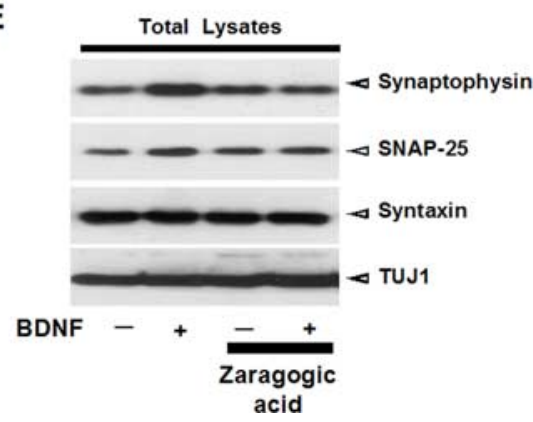

B

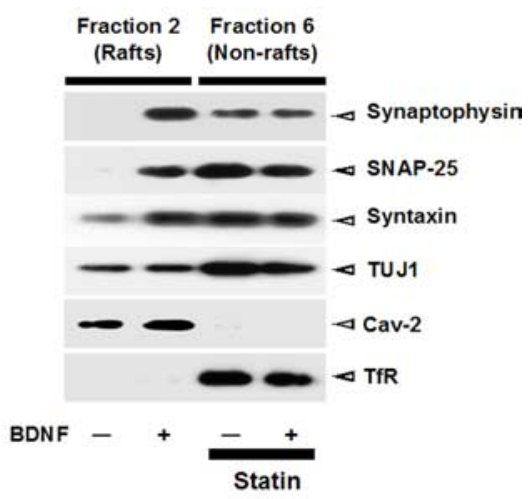

D

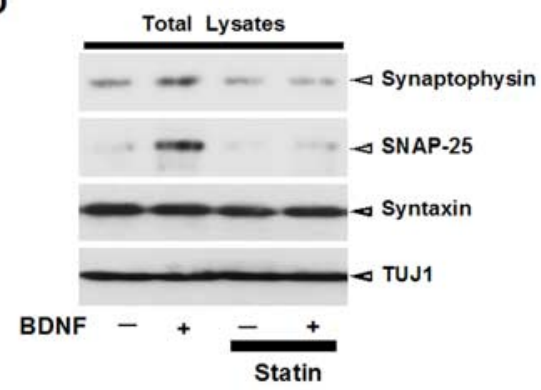

Figure 6. BDNF causes an increase in presynaptic proteins that accumulate in lipid rafts. Cortical neurons were cultured in the presence or absence of BDNF $(200 \mathrm{ng} / \mathrm{ml})$ and in the presence or absence of $10 \mu \mathrm{m}$ mevastatin or $100 \mu \mathrm{m}$ zaragozic acid for $3 \mathrm{~d}$. $\boldsymbol{A}$, BDNF-increased the number of synaptophysin-positive puncta. Cortical neurons were stained by using antibodies against MAP-2 (green; neuron marker) and synaptophysin (red; presynaptic marker). Scale bar, $50 \mu \mathrm{m}$. B, BDNF increases the presynaptic protein content of lipid rafts. Lipid raft and nonraft fractions were prepared as in Figure 5. Presynaptic proteins were detected with the indicated antibodies. C, Effect of mevastatin on the BDNF-induced increase in presynaptic puncta. Immunostaining was performed as in $\boldsymbol{A}$. The synaptophysin-positive puncta were determined by using Scion Image as described in Materials and Methods. Results (the means \pm SEM) are presented relative to - BDNF samples. The asterisk indicates a statistically significant difference from -BDNF samples (Student's t test; * $p<0.01$ ). D, E, Cholesterol synthesis inhibitors prevent the BDNF-dependent increase in lipid raft-associated presynaptic proteins. Total cell lysates were immunoblotted with the indicated antibodies. The BDNF-dependent increase in presynaptic proteins was inhibited by mevastatin $(\boldsymbol{D})$ and zaragozic acid $(\boldsymbol{E})$.

fraction, but not in the nonraft fraction. Moreover, BDNF increased the level of the lipid raft-organizing protein caveolin-2 in rafts.

More intriguingly, BDNF restricted an increase in presynaptic proteins in lipid rafts, suggesting that cholesterol-rich lipid rafts play a crucial role on BDNF-induced synapse development. It was demonstrated that (1) cholesterol itself regulates the availability of synaptic vesicles via a direct interaction with synaptophysin (Thiele et al., 2000), (2) SNAP receptor (SNARE) complex formation is cholesterol-dependent (Lang et al., 2001; Mitter et al., 2003), and (3) the association of SNARE complex with lipid rafts regulates exocytosis (Sala $\int \mathrm{n}$ et al., 2005). Presynaptic proteins are increased in cholesterol-rich lipid raft fractions concomitantly with cortical development (data not shown). Thus lipid rafts could provide an important structure for neurotransmitter release by promoting the interaction of cholesterol with synaptophysin or SNARE proteins.

Mevastain suppressed BDNF-induced increase in presynaptic proteins (Fig. 6D). Given that the mevalonate synthesis pathway through HMG-CoA regulates not only cholesterol synthesis but also isoprenoid production (Goldstein et al., 2006), mevastatin can suppress isoprenoid synthesis for the post-translational prenylation of cellular proteins such as Ras and Rho. However, the inhibitory effect of zaragozic acid on the BDNF-mediated increase in presynaptic proteins was comparable, but not partial, to that of mevastatin (Fig. 6D,E), leading to the interpretation that cholesterol synthesis, rather than isoprenoid synthesis, is crucial for synapse development.

BDNF elicits cholesterol synthesis for the development of a RRP of vesicles at presynaptic sites

Electrophysiological studies helped us to understand the role of BDNF-dependent cholesterol synthesis on synaptic development. First, although BDNF raised the number of synaptophysin-positive puncta and presynaptic proteins in hippocampal neurons (6-7 DIV), this effect was insufficient to provoke spontaneous mEPSCs. Remarkably, however, the electrophysiological study using hypertonic solution demonstrated that BDNF elicited exocytosis via a RRP of synaptic vesicles. This finding is conceptually consistent with a previous in vivo study that endogenous BDNF promotes the mobilization and/or docking of synaptic vesicles at presynaptic zones (Pozzo-Miller et al., 1999). Second, pretreatment with mevastatin prevented BDNF-dependent neurotransmitter release by a RRP of synaptic vesicles. Mevastatin itself did not affect sucrose-evoked EPSCs (Fig. 7C,D). These results together suggest that BDNF promotes the development of release machinery by the stimulation of cholesterol biosynthesis.

The full-length TrkB receptor is distributed at presynaptic and postsynaptic sites (Drake et al., 1999). It would be interesting to examine whether BDNF-promoted cholesterol biosynthesis stimulates the development of presynaptic and/or postsynaptic functions. Analysis of the neurotransmitter release evoked by a hypertonic solution (Rosenmund and Stevens, 1996) demonstrated that BDNF elicits a presynaptic function involving the exocytosis of a RRP of synaptic vesicles in developing neurons. On the other hand, BDNF had no significant effect on the amplitude of spontaneous mEPSCs (supplemental Fig. $1 B$, right, available at www.jneurosci.org as supplemental material), suggesting that BDNF is insufficient for the development of postsynaptic function at the developing stage. Additionally, a pharmacological 
study using mevastatin indicated that neither cholesterol nor BDNF-induced cholesterol synthesis had any effect on the amplitude of mEPSPs at postsynaptic sites (supplemental Fig. $1 B$, right, available at www.jneurosci.org as supplemental material). In marked contrast, mature hippocampal neurons regulate the shape and number of dendritic spines via cholesterol synthesis (Hering et al., 2003). To our knowledge the finding that BDNFpromoted cholesterol synthesis mediates a presynaptic function involving the exocytosis of a RRP of vesicles in developing neurons constitutes a novel mechanism for synapse development.

Recent reviews have highlighted a role for cholesterol-rich lipid rafts in neurotrophin signaling (Paratcha and Ibanez, 2002; Nagappan and Lu, 2005). In the present study, we demonstrated that BDNF acts as a novel regulator of cholesterol biosynthesis. BDNF also promoted the accumulation of presynaptic proteins in cholesterol-rich lipid rafts. Cholesterol and BDNF-dependent cholesterol biosynthesis may play an important role in presynaptic development. It will be important to determine how cholesterol-rich lipid rafts furnish a functional platform for presynaptic sites. Gaining a more profound understanding of the mechanisms by which neurotrophins regulate lipid metabolism is an important and intriguing issue that will provide a framework for future studies.

\section{References}

Arévalo JC, Yano H, Teng KK, Chao MV (2004) A unique pathway for sustained neurotrophin signaling through an ankyrin-rich membranespanning protein. EMBO J 23:2358-2368.

Barres BA, Smith SJ (2001) Neurobiology. Cholesterol-making or breaking the synapse. Science 294:1296-1297.

Bergstrom JD, Kurtz MM, Rew DJ, Amend AM, Karkas JD, Bostedor RG, Bansal VS, Dufresne C, VanMiddlesworth FL, Hensens OD, Liesch JM, Zink DL, Wilson KE, Onishi J, Milligan JA, Bills G, Kaplan L, Omstead MN, Jenkins RG, Huang L, et al. (1993) Zaragozic acids: a family of fungal metabolites that are picomolar competitive inhibitors of squalene synthase. Proc Natl Acad Sci USA 90:80-84.

Bibel M, Barde YA (2000) Neurotrophins: key regulators of cell fate and cell shape in the vertebrate nervous system. Genes Dev 14:2919-2937.

Brewer GJ, Torricelli JR, Evege EK, Price PJ (1993) Optimized survival of hippocampal neurons in B27-supplemented Neurobasal, a new serumfree medium combination. J Neurosci Res 35:567-576.

Brown MS, Goldstein JL (1999) A proteolytic pathway that controls the cholesterol content of membranes, cells, and blood. Proc Natl Acad Sci USA 96:11041-11048.

Chao MV (2003) Neurotrophins and their receptors: a convergence point for many signaling pathways. Nat Rev Neurosci 4:299-309.

de Chaves EI, Rusinol AE, Vance DE, Campenot RB, Vance JE (1997) Role of lipoproteins in the delivery of lipids to axons during axonal regeneration. J Biol Chem 272:30766-30773.

A
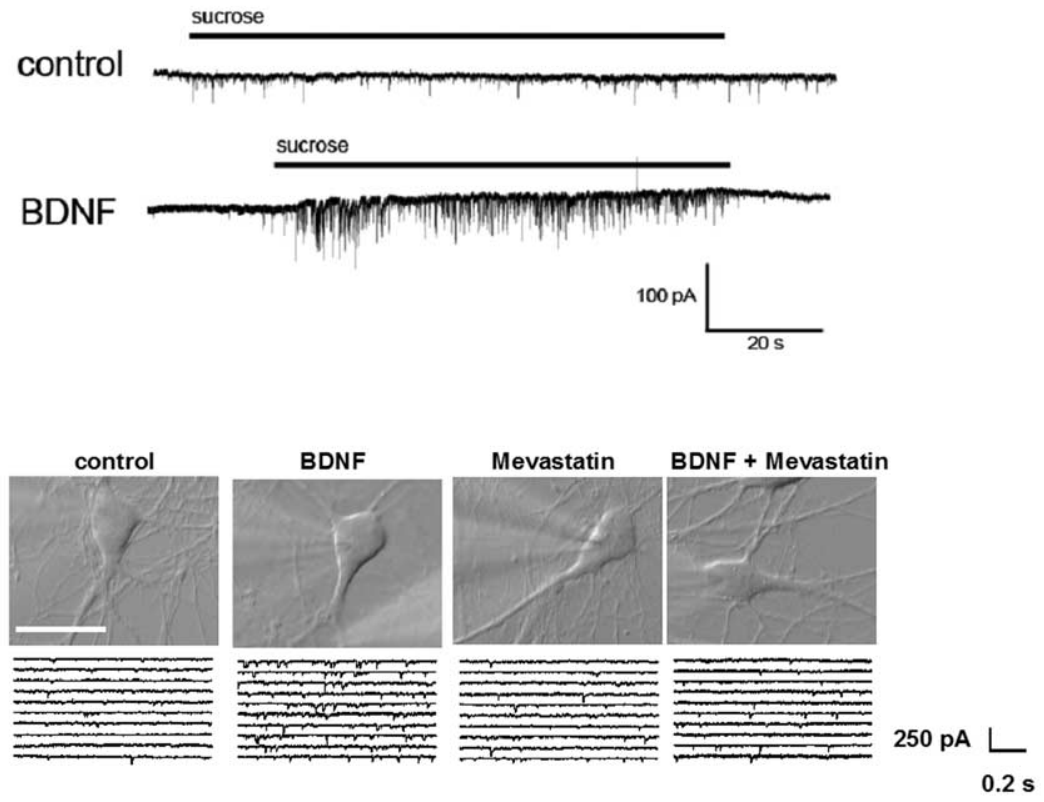

D

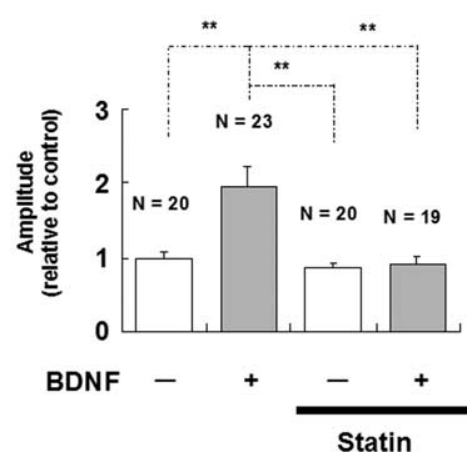

Figure 7. Effect of BDNF and/or mevastatin on a RRP of synaptic vesicles. Cultured hippocampal neurons (3-4 DIV) were treated with or without BDNF $(200 \mathrm{ng} / \mathrm{ml})$ and/or $10 \mu \mathrm{m}$ mevastatin for $3 \mathrm{~d}$. At 6-7 DIV, the hypertonic solution containing $100 \mathrm{~mm}$ sucrose was applied for recording sucrose-evoked EPSCS. This solution was applied to neurons for $35 \mathrm{~s}$, and the recording

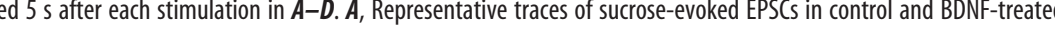
between the BDNF-treated cell and the control cell. $\boldsymbol{B}$, Sucrose-evoked responses from neuron the neurons treated with the indicated drugs. Scale bar, $30 \mu \mathrm{m}$. Summary of the frequency and amplitude of sucrose-evoked EPSCS. Data were normalized to that of control neurons (-BDNF; - Statin); $n=$ the number of independent coverslips. Asterisks indicate a statistically significant difference from control neurons (one-way ANOVA, followed by post hoc test; ${ }^{*} p<0.05 ;{ }^{* *} p<0.001$ ).

Demoulin JB, Ericsson J, Kallin A, Rorsman C, Ronnstrand L, Heldin CH (2004) Platelet-derived growth factor stimulates membrane lipid synthesis through activation of phosphatidylinositol 3-kinase and sterol regulatory element-binding proteins. J Biol Chem 279:35392-35402.

Drake CT, Milner TA, Patterson SL (1999) Ultrastructural localization of full-length TrkB immunoreactivity in rat hippocampus suggests multiple roles in modulating activity-dependent synaptic plasticity. J Neurosci 19:8009-8026.

Fan QW, Yu W, Gong JS, Zou K, Sawamura N, Senda T, Yanagisawa K, Michikawa M (2002) Cholesterol-dependent modulation of dendrite outgrowth and microtubule stability in cultured neurons. J Neurochem 80:178-190.

Figurov A, Pozzo-Miller LD, Olafsson P, Wang T, Lu B (1996) Regulation of synaptic responses to high-frequency stimulation and LTP by neurotrophins in the hippocampus. Nature 381:706-709. 
Goldstein JL, DeBose-Boyd RA, Brown MS (2006) Protein sensors for membrane sterols. Cell 124:35-46.

Guirland C, Suzuki S, Kojima M, Lu B, Zheng JQ (2004) Lipid rafts mediate chemotropic guidance of nerve growth cones. Neuron 42:51-62.

Hering H, Lin CC, Sheng M (2003) Lipid rafts in the maintenance of synapses, dendritic spines, and surface AMPA receptor stability. J Neurosci 23:3262-3271.

Kotti TJ, Ramirez DM, Pfeiffer BE, Huber KM, Russell DW (2006) Brain cholesterol turnover required for geranylgeraniol production and learning in mice. Proc Natl Acad Sci USA 103:3869-3874.

Krijnse-Locker J, Parton RG, Fuller SD, Griffiths G, Dotti CG (1995) The organization of the endoplasmic reticulum and the intermediate compartment in cultured rat hippocampal neurons. Mol Biol Cell 6:1315-1332.

Lang T, Bruns D, Wenzel D, Riedel D, Holroyd P, Thiele C, Jahn R (2001) SNAREs are concentrated in cholesterol-dependent clusters that define docking and fusion sites for exocytosis. EMBO J 20:2202-2213.

Lessmann V (1998) Neurotrophin-dependent modulation of glutamatergic synaptic transmission in the mammalian CNS. Gen Pharmacol 31:667-674.

Ma L, Huang YZ, Pitcher GM, Valtschanoff JG, Ma YH, Feng LY, Lu B, Xiong WC, Salter MW, Weinberg RJ, Mei L (2003) Ligand-dependent recruitment of the ErbB4 signaling complex into neuronal lipid rafts. J Neurosci 23:3164-3175.

Mauch DH, Nagler K, Schumacher S, Goritz C, Muller EC, Otto A, Pfrieger FW (2001) CNS synaptogenesis promoted by glia-derived cholesterol. Science 294:1354-1357.

Maxfield FR, Tabas I (2005) Role of cholesterol and lipid organization in disease. Nature 438:612-621.

McAllister AK, Lo DC, Katz LC (1995) Neurotrophins regulate dendritic growth in developing visual cortex. Neuron 15:791-803.

Metherall JE, Waugh K, Li H (1996) Progesterone inhibits cholesterol biosynthesis in cultured cells. Accumulation of cholesterol precursors. J Biol Chem 271:2627-2633.

Mitter D, Reisinger C, Hinz B, Hollmann S, Yelamanchili SV, Treiber-Held S, Ohm TG, Herrmann A, Ahnert-Hilger G (2003) The synaptophysin/ synaptobrevin interaction critically depends on the cholesterol content. J Neurochem 84:35-42.

Nagappan G, Lu B (2005) Activity-dependent modulation of the BDNF receptor TrkB: mechanisms and implications. Trends Neurosci 28:464-471.

Nakayama K, Kiyosue K, Taguchi T (2005) Diminished neuronal activity increases neuron-neuron connectivity underlying silent synapse formation and the rapid conversion of silent to functional synapses. J Neurosci 25:4040-4051.

Ohira K, Kumanogoh H, Sahara Y, Homma KJ, Hirai H, Nakamura S, Hayashi M (2005) A truncated tropomyosin-related kinase B receptor, T1, regulates glial cell morphology via Rho GDP dissociation inhibitor 1 . J Neurosci 25:1343-1353.

Paratcha G, Ibanez CF (2002) Lipid rafts and the control of neurotrophic factor signaling in the nervous system: variations on a theme. Curr Opin Neurobiol 12:542-549.

Patterson SL, Abel T, Deuel TA, Martin KC, Rose JC, Kandel ER (1996) Recombinant BDNF rescues deficits in basal synaptic transmission and hippocampal LTP in BDNF knockout mice. Neuron 16:1137-1145.

Pereira DB, Chao MV (2007) The tyrosine kinase Fyn determines the localization of TrkB receptors in lipid rafts. J Neurosci 27:4859-4869.

Pfrieger FW (2003) Role of cholesterol in synapse formation and function. Biochim Biophys Acta 1610:271-280.

Poo MM (2001) Neurotrophins as synaptic modulators. Nat Rev Neurosci $2: 24-32$.

Pooler AM, Xi SC, Wurtman RJ (2006) The 3-hydroxy-3-methylglutaryl coenzyme A reductase inhibitor pravastatin enhances neurite outgrowth in hippocampal neurons. J Neurochem 97:716-723.

Pozzo-Miller LD, Gottschalk W, Zhang L, McDermott K, Du J, Gopalakrishnan R, Oho C, Sheng ZH, Lu B (1999) Impairments in high-frequency transmission, synaptic vesicle docking, and synaptic protein distribution in the hippocampus of BDNF knockout mice. J Neurosci 19:4972-4983.

Qui MS, Green SH (1992) PC12 cell neuronal differentiation is associated with prolonged p $21^{\text {ras }}$ activity and consequent prolonged ERK activity. Neuron 9:705-717.

Rasika S, Alvarez-Buylla A, Nottebohm F (1999) BDNF mediates the effects of testosterone on the survival of new neurons in an adult brain. Neuron 22:53-62.

Reichardt LF (2006) Neurotrophin-regulated signaling pathways. Philos Trans R Soc Lond B Biol Sci 361:1545-1564.

Rose CR, Blum R, Pichler B, Lepier A, Kafitz KW, Konnerth A (2003) Truncated TrkB-T1 mediates neurotrophin-evoked calcium signaling in glia cells. Nature 426:74-78.

Rosenmund C, Stevens CF (1996) Definition of the readily releasable pool of vesicles at hippocampal synapses. Neuron 16:1197-1207.

Saito M, Benson EP, Saito M, Rosenberg A (1987) Metabolism of cholesterol and triacylglycerol in cultured chick neuronal cells, glial cells, and fibroblasts: accumulation of esterified cholesterol in serum-free culture. J Neurosci Res 18:319-325.

Sala $\int \mathrm{n}$ C, Gould GW, Chamberlain LH (2005) Lipid raft association of SNARE proteins regulates exocytosis in PC12 cells. J Biol Chem 280:19449-19453.

Shimano H (2001) Sterol regulatory element-binding proteins (SREBPs): transcriptional regulators of lipid synthetic genes. Prog Lipid Res 40:439-452.

Simons K, Toomre D (2000) Lipid rafts and signal transduction. Nat Rev Mol Cell Biol 1:31-39.

Suzuki S, Mizutani M, Suzuki K, Yamada M, Kojima M, Hatanaka H, Koizumi S (2002) Brain-derived neurotrophic factor promotes interaction of the Nck2 adaptor protein with the TrkB tyrosine kinase receptor. Biochem Biophys Res Commun 294:1087-1092.

Suzuki S, Numakawa T, Shimazu K, Koshimizu H, Hara T, Hatanaka H, Mei L, Lu B, Kojima M (2004) BDNF-induced recruitment of TrkB receptor into neuronal lipid rafts: roles in synaptic modulation. J Cell Biol 167:1205-1215.

Tacer KF, Haugen TB, Baltsen M, Debeljak N, Rozman D (2002) Tissuespecific transcriptional regulation of the cholesterol biosynthetic pathway leads to accumulation of testis meiosis-activating sterol (T-MAS). J Lipid Res 43:82-89.

Takamori S, Holt M, Stenius K, Lemke EA, Gronborg M, Riedel D, Urlaub H, Schenck S, Brugger B, Ringler P, Muller SA, Rammner B, Grater F, Hub JS, De Groot BL, Mieskes G, Moriyama Y, Klingauf J, Grubmuller H, Heuser J, et al. (2006) Molecular anatomy of a trafficking organelle. Cell 127:831-846

Takei N, Sasaoka K, Inoue K, Takahashi M, Endo Y, Hatanaka H (1997) Brain-derived neurotrophic factor increases the stimulation-evoked release of glutamate and the levels of exocytosis-associated proteins in cultured cortical neurons from embryonic rats. J Neurochem 68:370-375.

Takei N, Kawamura M, Hara K, Yonezawa K, Nawa H (2001) Brain-derived neurotrophic factor enhances neuronal translation by activating multiple initiation processes: comparison with the effects of insulin. J Biol Chem 276:42818-42825.

Tapley P, Lamballe F, Barbacid M (1992) K252a is a selective inhibitor of the tyrosine protein kinase activity of the Trk family of oncogenes and neurotrophin receptors. Oncogene 7:371-381.

Tartaglia N, Du J, Tyler WJ, Neale E, Pozzo-Miller L, Lu B (2001) Protein synthesis-dependent and -independent regulation of hippocampal synapses by brain-derived neurotrophic factor. J Biol Chem 276 37585-37593.

Thiele C, Hannah MJ, Fahrenholz F, Huttner WB (2000) Cholesterol binds to synaptophysin and is required for biogenesis of synaptic vesicles. Nat Cell Biol 2:42-49.

Valenza M, Rigamonti D, Goffredo D, Zuccato C, Fenu S, Jamot L, Strand A Tarditi A, Woodman B, Racchi M, Mariotti C, Di Donato S, Corsini A Bates G, Pruss R, Olson JM, Sipione S, Tartari M, Cattaneo E (2005) Dysfunction of the cholesterol biosynthetic pathway in Huntington's disease. J Neurosci 25:9932-9939.

Vance JE, Pan D, Campenot RB, Bussiere M, Vance DE (1994) Evidence that the major membrane lipids, except cholesterol, are made in axons of cultured rat sympathetic neurons. J Neurochem 62:329-337.

Vance JE, Hayashi H, Karten B (2005) Cholesterol homeostasis in neurons and glial cells. Semin Cell Dev Biol 16:193-212.

Wang T, Xie K, Lu B (1995) Neurotrophins promote maturation of developing neuromuscular synapses. J Neurosci 15:4796-4805.

Zuccato C, Ciammola A, Rigamonti D, Leavitt BR, Goffredo D, Conti L, MacDonald ME, Friedlander RM, Silani V, Hayden MR, Timmusk T, Sipione S, Cattaneo E (2001) Loss of huntingtin-mediated BDNF gene transcription in Huntington's disease. Science 293:493-498. 